\title{
Walking in My Shoes: Imagined Synchrony Improves Attitudes Towards Out-groups
}

\author{
Gray Atherton ${ }^{1}$ (I) Liam Cross ${ }^{1}$
}

Received: 4 October 2019/ Accepted: 13 August 2020/Published online: 29 September 2020

(C) The Author(s) 2020

\begin{abstract}
People are prone to dividing others into the categories of 'us' and 'them'. This can be particularly detrimental to minorities who may experience social exclusion, prejudice, and reduced access to equal opportunities. One method of improving intergroup relations is to create opportunities for contact. Common contact interventions have members of different groups meet and engage in conversation. There are also non-verbal embodied intergroup activities that produce the same effects. Previous work has shown that the pro-social effects of coordination may be linked to whether co-actors are classed as in or out-group members. The current study explored whether imagining walking in synchrony with inor out-group members changed majority members' attitudes towards those individuals. Imagining walking in synchrony fostered greater increases in empathy and decreases in negative attitudes only towards minority group members following imagined coordination (not ingroups). Implications and future directions are discussed.
\end{abstract}

Keywords Coordination - Entrainment - Synchrony · Attitudes · Pro-sociality · Group processes · Stereotypes

Gray Atherton and Liam Cross have contributed equally to this work.

Liam Cross

drliamcross@gmail.com

1 Department of Psychology, Edge Hill University, Liverpool L39 4QP, UK

\section{Introduction}

People are social creatures; we define ourselves by our affiliations, and in turn we gravitate towards the people who we see in ourselves. Through this gradual process of recognizing the self in others, we develop heuristics that allow us to quickly recognize the 'us' in 'them', or alternatively recognize how 'they' are not like 'us' (Turner, 2010).

On a purely psychological level, research has shown strong effects of group dynamics on our social response patterns. When faced with either an in- or out-group member, we will consistently favour those who we perceive to be 'like us', both on an explicit and implicit level, particularly if we belong to the majority (Dasgupta, 2004). While in many ways understandable, given early developmental exposure to our own ethnic group (Kelly et al., 2009), such favouritism can lead to social problems. This is particularly pronounced in the context of minority groups who experience multi-layered disadvantages due to their out-group status.

While the social divide between minority and majority group members has profound effects on the quality of life for minorities at the most pragmatic level, including identity-related stress (Utsey, Chae, Brown, \& Kelly, 2002) and reduced access to equal opportunities (Wrench, Rea, \& Ouali, 2016), it can harm those in the majority as well. While homophily, or relationships within one's own culture may be the norm (McPherson, Smith-Lovin, \& Cook, 2001), it may not be entirely positive. Research indicates that individuals who engage with members of different social groups experience a multitude of benefits; amongst others, multicultural experiences foster creativity at the individual level (Leung \& Chiu, 2010) and group level (Tadmor, Satterstrom, Jang, \& Polzer, 2012). More 
broadly, as detailed by Gurin (1999), integration of minorities into the majority allows those in the majority to recognize similarities between groups while simultaneously appreciating cultural differences; importantly, these outcomes enable individuals to flourish in a diverse society.

Research shows that coming into contact, and having a positive interaction, with a member of a minority group improves perceptions of that entire group (Pettigrew \& Tropp, 2006). The effects of such interactions are stark. For instance, individuals from a majority group who experience positive contact (Reimer et al., 2017), and count minority group members as friends (Dirksmeier, 2014), are significantly more likely to advocate for minority rights. Indeed, simply living in areas where one encounters minority members can improve attitudes towards them (Piekut \& Valentine, 2017). Similarly, the ramifications of being less exposed to culturally diverse groups can conversely carry negative consequences for minority experiences and policies.

One example of this can be found in the UK, a country with a diverse cultural landscape. In London, there is a strong multicultural presence (over 55\% of residents are non-British) and the majority support immigration (Krausova \& Vargas-Silva, 2013). Those who live outside of London experience less minority presence in general, significantly less integration, and largely view immigration negatively; only $28 \%$ view it positively according to recent census reports (Park, Bryson, \& Curtis, 2014). Despite decades of immigration policies such as those from former British colonies who gained citizenship throughout the Windrush generation (Phillips \& Phillips, 1998), on the whole the UK remains divided as to whether the country's changing cultural landscape is positive or detrimental to the British identity (Clery, Curtice, \& Harding, 2016).

This is perhaps best encapsulated in the most politically important issue the UK has faced recently, Brexit, a referendum on which citizens voted to leave the European Union. Census data indicate that one of the key reasons for this result may have been tied to immigration (Clery et al., 2016), perhaps driven in part by responses to media reports of high volumes of refugees outside the EU entering Europe under protected status (Goodwin \& Milazzo, 2015). Indeed, some research has suggested that media reporting may be influential in the formation and maintenance of attitudes towards refugees (Lynott et al., 2019). When assessing geographically the results of the referendum, the 'North-South' divide played a key role in motivating those in the Midlands and North who experience greater deprivation, less education, and less multicultural integration, to vote Leave (McCann, 2016). Voting patterns were in line with patterns of acculturation; those rooted to a local area were more likely to vote Leave, while those were mobile were more likely to vote Remain (Lee, Morris, \& Kemeny,
2018), speaking to the effect out-group exposure has on decision making (Oishi, 2010). Thus, it seems imperative that individuals be in contact with members of different groups in an effort to increase acceptance and understanding of cultures other than one's own. Below we have outlined on alternative method of out-group contact.

The English language is littered with metaphor, and, as detailed by Webb, Rossignac-Milon, and Higgins, (2017) many of these metaphors use our most basic experience of moving through space and time, walking, to describe our less tangible social experiences. For instance, we feel a connected to those who we view as being 'in sync' with us, while, conversely, we may become distant from others by 'drifting apart'. It's possible, however, to heal these divides by 'moving forward', 'putting it behind us', 'meeting in the middle' or 'getting back on track'. Furthermore, we can empathize with others by 'walking in their shoes.' In many ways, these lower level, movement-based analogies are describing group-level distinctions that occur at the subconscious level. People who move with you are in your group, and by making the effort to move with someone, you are opening the possibility of being in the same group. In this way, it becomes clear that while there are certainly cognitive mechanisms that shape relationships with others, such as shared views, values and beliefs, there are also simpler, embodied mechanisms that equally account for shared social connections.

This has particularly strong ramifications for majority and minority group members, and possible interventions for reducing group divides. One possible means of reducing negative stereotypes may be to have people engage in coordinated movement with individuals from disenfranchised groups, such as walking in synchrony with them. This is supported by behavioural studies which show that interpersonal coordination can to lead to greater pro-sociality amongst co-actors by increasing rapport (Hove \& Risen, 2009), affiliation (Reddish, Fischer, \& Bulbulia, 2013), cooperation (Cross, Wilson, \& Golonka, 2016) and helping (Cross, Micheal, Wilsdon, Henson, \& Atherton, 2020) amongst those who take part. Even imagining coordinating has been shown to lead to some of the same social consequences as actually coordinating (i.e. Dong, Dai, \& Wyer, 2015; Cross, Atherton, Wilson, \& Golonka, 2017; Atherton, Sebanz, \& Cross, 2019).

Imagined scenarios retain many of the essential spatial, temporal, perceptual, neural, and motoric properties of the events they represent. Specifically, there appears to be neural and cognitive overlap in the operations that support mental simulation and overt behaviour (Fadiga \& Craighero, 2004). Similar patterns of physiological activity are seen during mental simulations of certain behaviours as are seen during the actual physical execution of the behaviour. Bird (1984) demonstrated that EMG measurements from 
the arm were similar when mental rehearsing ball throws as when the throws were physically executed. Furthermore, the same auditory cortical areas are active during imagined versus actual experiences of listening to music (Halpern, 1988; Zatorre, Halpern, Perry, Meyer, \& Evans, 1996). Mental rehearsal has also been shown to have a positive effect on performance, and mentally practicing a motor skill enhances performance across a variety of activities (Landers, 1983; Driskell, Copper, \& Moran, 1994). Mental simulation of an event seems to have both neural and cognitive overlap without actually executing or experiencing that event.

Mental simulation of social encounters can also elicit responses similar to the real experiences (Dadds, Bovbjerg, Redd, \& Cutmore, 1997). For instance, Crisp and Turner (2009) showed how simply imagining a positive interaction with an out-group member can increase one's positive perceptions of the target group. Similarly, imagining being in a crowd reduces people's helping behaviour on a subsequent task, in line with the bystander effect (Garcia, Weaver, Moskowitz, \& Darley, 2002). Previous work has also shown that not only are people able to successfully perform imagined coordinated actions (Vesper, Knoblich, \& Sebanz, 2014), but that doing so leads to similar increases in pro-social attitudes that are shown to follow actual coordination (Cross et al., 2017; Atherton et al., 2019). Some speculate that coordination may have long been used as a tool to foster a common group mentality amongst co-actors (McNeil, 1995). Multiple evolutionary theorists state that early coordinated actions such as song and dance served to both strengthen bonds within-groups and display those bonds across groups (Cross, 2009; Hagen \& Bryant 2003; Merker, 2000).

If this is true, then we might expect that coordination's social effects will differ depending upon whether the individuals one is coordinating with are perceived to already be a part of one's same social group. There is now a growing body of work supporting the idea that such effects are indeed strongly intertwined with group dynamics. Miles, Lumsden, Richardson, and Macrae (2011) for instance found that people are more likely to coordinate with individuals who are part of a different minimal group than those that are part of the same minimally created social group. This led the authors to hypothesize that coordination may be used a vehicle to foster a superordinate group amongst co-actors. In support of this, research has shown that the increased social bonding and cooperation following coordination is either more apparent (Pearce et al., 2016) or in some cases only present (Tunçgenç \& Cohen, 2016; Cross, Turgeon, \& Atherton, 2019a) if co-actors belong to different groups. This has led some to conclude that coordination's social consequences may be underpinned by group dynamics, as it leads co-actors to view each other in more common group terms (Cirelli, 2018; Cross et al. 2019a; Miles et al., 2011). For a more detailed review of supporting evidence for this hypothesis, see Cross, Turgeon, and Atherton (2019b).

While the vast majority of work exploring the social consequences of coordination to date have tested this using incidental or minimal experimentally created groups (Good, Choma, \& Russo, 2017; Miles et al., 2011; Tunçgenç \& Cohen, 2016), similar effects have also been shown when people are coordinating with members of different socio-culturally significant groups (i.e. Pearce et al., 2016; Cross et al. 2019a). However, in these studies, although 'real' groups were utilized, these groups were not particularly opposed (i.e. members of different universities). The only work to explore the role of coordination in intergroup relations towards a disenfranchised out-group examined changes in Hungarian's attitudes towards the Roma (Atherton et al., 2019), an ethnic minority group which is particularly marginalized throughout Central Europe (Kende, 2000). This work showed that both actual and imagined synchronous walking led to significant changes in attitudes towards a socio-culturally significant out-group. However, it remains unclear if and how imagining walking in synchrony with someone affects our attitudes of and empathy towards those who are part of the same versus an opposing social group.

Thus, this work explores how imagining walking in synchrony affects empathy and prejudicial attitudes towards British citizen's perceptions of either other British citizens or Middle Eastern refugees. We recruited participants form the Midlands and North of the UK as these areas tend to be the least integrated areas of England (McCann, 2016). We predicted that there would be positive changes in empathy and attitudes towards refugees, but not fellow UK citizens, following imagined synchronous walking.

\section{Method}

\section{Design and Participants}

The study had a between groups design with a single independent variable, group type, where UK participants imagined walking with either fellow UK citizens (ingroup) or Middle Eastern Refugees currently residing in Europe (out-group). UK citizens who were born in, and currently residing in, the UK, and who were over 18 and spoke English, were invited to take part. Participants were recruited through the Sona system at two universities in the Midlands and the North of the UK as well as by posting advertisements on social media groups. One hundred and 
thirty people took part in the survey ( 85 females, 44 males, 1 other; $M_{\text {age }}=28.42$ year, $\mathrm{SD}_{\text {age }}=11.52$ ). In order to maintain an element of control over the online setting, several check questions were asked during the survey (see the following section). Anyone who failed these check questions were excluded from further analysis $(n=43)$, which left a final sample of 87 participants $(44 / 43$ per condition, 56 females, 30 males, 1 other, $M_{\text {age- }}$ $=29.41$ year, $\mathrm{SD}_{\text {age }}=12.15$ ). Power analysis confirmed that this sample was adequately powered ( $87 \%$ power) for $t$ tests using effect size estimates of $d=0.5$ (as seen in Cross et al., 2017). The University of Wolverhampton Ethics Review Board approved the experiment, and the experiment was carried out in accordance with the relevant guidelines. All participants gave full informed consent.

\section{Procedure and Materials}

This study was conducted online via the survey platform Qualtrics. Participants were first asked if they were born in the UK, were currently a UK citizen, if they were over the age of 18 , and if they were in a quiet place where they would not be disturbed. Anyone who answered no to any of these questions were informed they were not eligible to take part and thanked for their interest. Participants were then informed the study was about how people imagine doing things with people who have either the same backgrounds (fellow UK citizens) or different backgrounds (Middle Eastern Refugees) as themselves, and were shown pictures of these individuals. The pictures were headshots that showed both a Caucasian male and female and a Middle Eastern male and female, and images were matched for size, background and colour. Participants were then randomly assigned to one of the two conditions and told that for the rest of the study they will be imagining performing tasks with the two individuals in the two pictures shown, i.e. either Middle Eastern refugees or UK citizens. Participants were asked to spend some time looking at the people in the pictures and were blocked from moving on from this page until $30 \mathrm{~s}$ had passed.

Following this, participants were asked to fill in measures of empathy and attitudes. All responses were given on a continuum response scale, ranging from not at all to very much so, which generated a number between 0 and 100. Empathy was measured using three questions from the felt understanding measure (Holoien, 2016), and asked how well can you understand the two individuals, how well can you feel what they are feeling and how much empathy do you have for them. Attitudes were measured using three questions from the prejudicial attitudes measure (Hoyt \& Goldin, 2016), and asked how happy would you be to have the two individuals as your boss, sexual partner and to have them join your close family in marriage.
Participants were then asked to spend two minutes imagining walking in synchrony with the two individuals (relevant pictures of the individuals were again shown on this page). They were asked to imagine all their legs rising and falling together in unison and the sound of their feet hitting the floor at the same time. They were told when they were ready, they should then progress to the next page, close their eyes, and imagine walking with the target individuals for two minutes. The next page again displayed the instructions and participants were blocked from progressing until two minutes had passed. The number of times participants attempted to click through this page was measured in the background, but participants were unaware of this.

Following this, participants were asked how coordinated they imagined the walking to be, and how enjoyable they found the task. These items ranged from not at all to very much so. They then responded to identical measures of empathy and attitudes. As a final check that participants had adequately engaged with the task, they were asked to pick out the two individuals they had been imagining interacting with. The correct target individuals were displayed alongside three closely matched foil pairs, mixing in similar male and female images from each type to make three foil pairs per target type. Participants were also asked whether they had imagined walking or jumping, whether they did the survey alone, and whether they were interrupted during the imagination task in order to identify anyone who had not adequately engaged with the task. Participants were then debriefed and thanked for their time.

\section{Results}

We first excluded anyone who incorrectly identified the individuals they had been shown in the task, or anyone who reported imaging jumping rather than walking, who reported being in a public place, who reported being interrupted during the imagination task, or anyone who attempted to click through the imagination task multiple times. This exclusion plan was in place before data collection in order to ensure that our final sample had adequately engaged with the task. Table 1 shows the number of exclusions by conditions. We then checked that the dependent variable measures held up to scale analysis using Cronbach's alphas (pre scores), all had acceptable alphas [Empathy ( $a=.739)$, and Attitudes $(a=.819)$ ]. We therefore made composite change scores for these measures by first subtracting each before-score from the after-score and then averaging the relevant items for each construct. Whether the distributions of our data violated normality assumptions was then checked using a ShapiroWilkes tests. Results of these tests can be found in Table 2 . 
Table 1 Total exclusions by condition

\begin{tabular}{lcc}
\hline & In-group & Out-group \\
\hline Attempted to click through imagination task & 13 & 16 \\
Misidentified individuals & 3 & 0 \\
Misidentified task & 5 & 2 \\
Reported interruptions & 12 & 4 \\
Reported not being alone & 3 & 2 \\
Total participants excluded & 24 & 19 \\
Remaining $n$ & 44 & 43 \\
\hline
\end{tabular}

Table 2 Normality checks

\begin{tabular}{lll}
\hline & In-group & Out-group \\
\hline Coordination & $\mathrm{SW}(44)=.95, p=.05$ & $\mathrm{SW}(43)=.82,<.001^{*}$ \\
Enjoyment & $\mathrm{SW}(44)=.94, p=.20$ & $\mathrm{SW}(43)=.95,=.08$ \\
Empathy & $\mathrm{SW}(44)=.82, p<.001^{*}$ & $\mathrm{SW}(43)=.96,=.19$ \\
Attitude & $\mathrm{SW}(44)=.87, p<.001 *$ & $\mathrm{SW}(43)=.88,<.001^{*}$ \\
\hline
\end{tabular}

*Denotes distributions which significantly deviated from normality

Wherever normality was violated, nonparametric tests were used. Descriptive statistics for the following results can be found in Table 3.

While on average those in the out-group condition did report imagining walking in a more coordinated way than those in the in-group condition, a Mann-Whitney $U$ test confirmed this difference did not reach significance $(u=791.5, p=.187, Z=1.319, r=0.141)$. An independent samples $T$ test confirmed that those in the out-group condition reported enjoying the task significantly more than those in the in-group condition $(t(85)=2.667$, $p=.009, d=0.572$ ). As shown in Fig. 1, Mann-Whitney $U$ tests confirmed that those in the out-group condition reported significantly greater positive changes in Empathy ( $U=594.0, p=.003, z=2.989, r=0.32)$ and Attitudes $(U=688.0, p=.028, z=2.191, r=0.235)$ post-imagined coordination than those in the in-group condition. We also investigated which measures showed significant changes from 0 using a one sampled test and one-sample Wilcoxon signed rank test with 0 as the hypothesized mean/median.
For Empathy, only the out-group condition's $(Z=787.0$, $p<.001, r=0.578$ ), but not the in-group condition's $(t(44)=1.234, p=.224, d=0.186)$ change scores significantly increased from 0 . For attitudes, only the out-group condition's $(Z=568.0, p=.034, r=0.324)$, but not the ingroup condition's $(Z=482.0, p=.703, r=0.057)$, change scores significantly increased from 0 .

\section{Discussion}

Those who had imagined coordinating with members of an out-group saw significantly greater empathy and attitude change scores (cf. in-group). In line with this, change scores were significantly greater than 0 only in the outgroup condition, but not the in-group condition. These findings show that increases in empathy and positive attitudes only occurred after participants imagined coordinating with out-group but not in-group members. The findings reported here therefore replicate those of Atherton et al. (2019) in a new context, showing that imagined coordination can be utilized to foster better attitudes towards members of disenfranchised groups. Furthermore, they

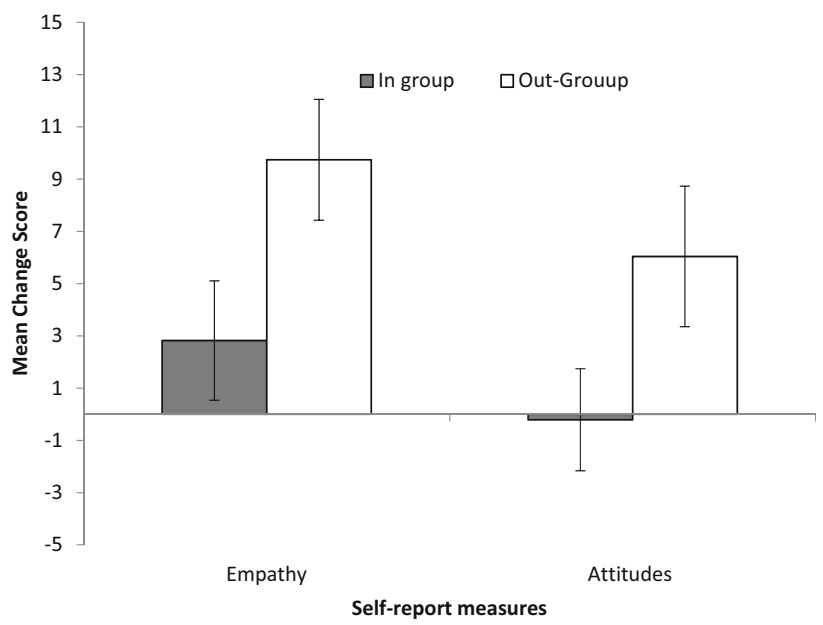

Fig. 1 Mean and standard errors for all self-report change scores

Table 3 Descriptive statics for all dependent variables

\begin{tabular}{|c|c|c|c|c|c|c|c|c|}
\hline & \multicolumn{4}{|c|}{ In-group } & \multicolumn{4}{|c|}{ Out-group } \\
\hline & Mean & SD & Mdn & Range & Mean & SD & Mdn & Range \\
\hline Coordination & 71.57 & 21.38 & 70.5 & $22-100$ & 75.74 & 25.49 & 81.5 & $0-100$ \\
\hline Enjoyment & 46.84 & 27.92 & 51.33 & $0-100$ & 62.50 & 26.79 & 64.4 & $0-100$ \\
\hline Empathy & 2.82 & 15.14 & -.67 & -24.33 to 55.67 & 9.74 & 15.17 & 8 & -22.0 to 59.0 \\
\hline Attitudes & -0.21 & 12.94 & -1.60 & -30.33 to 45.67 & 6.04 & 17.70 & 2.56 & -27.0 to 63.33 \\
\hline
\end{tabular}


highlight that this effect is modulated by group membership, further supporting the idea that coordination doesn't unilaterally increase pro-social behaviours, but differentially changes perceptions of in-group and out-group members.

As previously discussed, other work has shown that the social consequences of coordination depend upon with whom one is coordinating. That is, people are more likely to coordinate with members of different minimal groups (Miles et al., 2011), and the pro-social effects of coordination are greater when people are coordinating with individuals whom are part of a different social group (Cross et al. 2019a; Tunçgenç \& Cohen, 2016). This adds further weight to the growing body of work suggesting coordination's social effects may be modulated by group dynamics, and thus may be better thought of as pro-group rather than pro-social (Cross et al. 2019b).

The idea that coordination may more broadly affect the emergence of social units is grounded in research that links coordination with group formation and categorization, a process described by Tajfel (1982) as occurring after individuals begin to perceive similarities between themselves and other group members. A large body of research suggests that observing coordination changes our perceptions of how entitative those actors are perceived. For instance, both stick figures and actual people who wave in synchrony are perceived as higher in entitativity compared with those who wave out of synchrony (Lakens, 2010; Lakens \& Stel, 2011). Similar effects have also been shown when people process visual and auditory information associated with co-walkers' footsteps (Miles, Nind, \& Macrae, 2009). Fawcett and Tunçgenç (2017) also highlight how coordination is intimately tied to group dynamics, as infants who observe coordinating actors judge them using interdependent (group) rather than independent (individual) criterion. Interestingly, Lumsden, Miles, \& Macrae, (2012) found that group-level perceptions can also influence judgements of synchrony. In this study they found participants judged dyads of people with similar skin tones to be more synchronous than dyads with dissimilar skin tones, though in reality the level of coordination was the same. The work we report here goes beyond these findings, showing that coordinating with members of other social groups can have positive impacts on how we perceive those groups.

This study also suggests that people also change their group categorizations after participating in coordinated movement. For instance, Good, Choma, and Russo (2017) showed that following a multi-group coordination task, children were more likely to cooperate with whichever group they had coordinated with and distinguished between groups by accounting for coordinated movement. For instance, children were more likely to rate their cohort as:
(1) individuals if there was no coordination; (2) two groups if they coordinated with one group but not the other; (3) one group if everyone coordinated together. Pearce, Launay, MacCarron, \& Dunbar, (2017) also found that after group singing, self-reported increases in social bonding were driven by changes at the collective (specific to a group relations and identities) rather than relational (specific to individual relations) level. Cross et al. (2017) also showed that imagining coordinating leads individuals to view themselves in more interdependent, or group level terms, rather than individual terms. Finally Cross et al. (2020) showed that changes in viewing oneself and ones co-actor in individual versus common group terms mediated coordination's effect on helping behaviour. Thus, it appears that coordination's social effects are particularly tied to group dynamics. But why might imagining coordinating with an out-group member cultivate more empathy and pro-social attitudes compared to an in-group member?

One explanation is that moving in time with another person allows you to incorporate that person into your ingroup, and thus certain changes should only be observed towards out-group rather than existing in-group members. Specifically, when we coordinate with somebody who we already categorize as a common group member, coordination has no vehicle in which to shift our perceptions. There is extensive literature supporting this explanation in studies using both minimally created and naturally occurring groups (see Cross et al. 2019b, for a review). For instance, Tunçgenç and Cohen (2016) found that coordination only served to reduce social distance and increase bonding when children coordinated with members of different minimally created social groups. Similar findings have also been shown in adult samples with naturally created groups, such as those used in this study. Pearce et al. (2016) had members of different university fraternities sing in time with either members of the same or a different fraternity. An increase in closeness to the group was significantly greater when people sang with members of a different fraternity. Thus, the authors posited that group singing helped cultivate a collective identity between in- and out-group co-actors. A recent study by Cross et al. (2019a) also showed that coordination only affected cooperation when people coordinated with members of different socio-culturally significant groups (from a different university and nationality), not members of the same group (same university and nationality).

There are several interesting areas of future study that could follow from this work. One comes from a study from Tamborini et al. (2018) in which participants danced in a coordinated way with an avatar who was their same or different race. Results revealed an interaction between outgroup level trust and the race of the avatar: those who 
danced with a same race avatar were less trusting of the other race, and those who danced with a different race avatar were more trusting of that race. In other words, coordination with an in-group negatively affected trust of an out-group. This makes sense if coordination acts to reinforce a common group mentality amongst those involved, as in-group favouritism is closely tied with outgroup denigration. Future work will want to further investigate this effect, in line with work showing a 'darker side' of coordinated movement including increased conformity and willingness to follow harmful orders (Wiltermuth, 2012).

Future work may also want to investigate the differences between individuals with particularly polarized pre-existing attitudes towards immigration, or social identities that align with more extreme views on this topic. For instance, Homola and Tavits (2018) found that reported contact reduced immigration-related fears in individuals who identified as leftists but had no effect on those who identified as rightist. This is somewhat contradictory to contact studies that report the strongest changes in prejudice following contact occurs in those with the highest baseline of prejudicial attitudes (Hodson, 2011). Thus, it would be of interest to explore the intersection between identity, prejudicial attitudes and contact.

There are several implications of this work with regard to decreasing prejudicial attitudes towards minority group members in tangible ways. For instance, research suggests that individuals who practice certain types of synchronous movements associated with mindfulness such as yoga have an increased ability to decrease implicit prejudices through cognitive control (Dasgupta, 2009). Researchers have also linked meditative practice to decreases in prejudice, which is mediated by increases in empathy, in line with the findings from this study (Hunsinger, Livingston, \& Isbell, 2014). Thus, it may be that a useful intervention to improve intergroup relations in real-life settings may be to have inand out-group members alike engage in coordinated movements, perhaps in public space, that also include elements of mindfulness including group yoga and tai chi. Indeed, actual movement may particularly enhance the effects found in this study. For instance, Tarr, Launay, Cohen, and Dunbar (2015) found in a dancing task that not only synchrony, but physical exertion, played a role in increasing the social bond between co-actors through the release of endorphins. Thus, future research will want to further investigate the application of this work by exploring ways to publicly engage people in coordinated activities to positively affect intergroup relations.

In summary, our findings show that imagined coordination can cultivate greater empathy, and more positive attitudes, towards out-group members. They also show that these effects are distinct to people whom are not already classed as common group members. One particular strength of the current study is that it utilized real-life inand out-groups that are socio-culturally significant to study changes in pro-sociality following coordination. As such, it bolsters the evidence showing the social side of coordination, while also revealing the possible uses for engaging in synchrony to improve intra-group conflict.

Funding This project did not utilize any funding.

Data Availability For data requests please email the corresponding author.

\section{Compliance with Ethical Standards}

Conflict of interest The authors have no conflicting or competing interests to declare.

Ethics Approval Ethics was approved by the Psychology department at the University of Wolverhampton.

Consent to Participate All participants gave full informed consent to participate.

Consent for Publication All participants gave consent for their data to be used in publication.

Open Access This article is licensed under a Creative Commons Attribution 4.0 International License, which permits use, sharing, adaptation, distribution and reproduction in any medium or format, as long as you give appropriate credit to the original author(s) and the source, provide a link to the Creative Commons licence, and indicate if changes were made. The images or other third party material in this article are included in the article's Creative Commons licence, unless indicated otherwise in a credit line to the material. If material is not included in the article's Creative Commons licence and your intended use is not permitted by statutory regulation or exceeds the permitted use, you will need to obtain permission directly from the copyright holder. To view a copy of this licence, visit http://creativecommons.org/licenses/by/4.0/.

\section{References}

Atherton, G., Sebanz, N., \& Cross, L. (2019). Imagine all the synchrony: The effects of actual and imagined synchronous walking on attitudes towards marginalised groups. PLOS ONE, 14(5), $\mathrm{e} 0216585$.

Bird, E. I. (1984). EMG quantification of mental rehearsal. Perceptual and Motor Skills, 59(3), 899-906.

Cirelli, L. (2018). How interpersonal synchrony facilitates early prosocial behaviour. Current Opinion in Psychology, 20, 35-39.

Clery, E., Curtice, J., \& Harding, R. (2016). British social attitudes: The 34th report. London: NatCen Social Research.

Crisp, R. J., \& Turner, R. N. (2009). Can imagined interactions produce positive perceptions? Reducing prejudice through simulated social contact. American Psychologist, 64(4), 231.

Cross, I. (2009). The evolutionary nature of musical meaning. Musicae Scientiae, 13(2), 179-200.

Cross, L., Atherton, G., Wilson, A. D., \& Golonka, S. (2017). Imagined steps: Mental simulation of coordinated rhythmic 
movements effects on pro-sociality. Frontiers in Psychology, 8 , 1798.

Cross, L., Micheal, J., Wilsdon, L., Henson, H., \& Atherton, G. (2020). Still want to help: Entrainments effects on helping behaviour after a 24-hour delay. Acta Psychologica. https://doi.org/10.1016/j.actpsy.2020.103062.

Cross, L., Turgeon, M., \& Atherton, G. (2019a). Moving with the incrowd: Interpersonal entrainment and cooperation in in- vs. out groups. Current Psychology. https://doi.org/10.1007/ s12144-019-00283-0.

Cross, L., Turgeon, M., \& Atherton, G. (2019b). How moving together binds us together: A review of the socio-emotional effects of interpersonal entrainment. Open Psychology, 1, 273-302. https://doi.org/10.1515/psych-2018-0018.

Cross, L., Wilson, A. D., \& Golonka, S. (2016). How moving together brings us together: When coordinated rhythmic movement affects cooperation. Frontiers in Psychology, 7, 1983.

Dadds, M. R., Bovbjerg, D. H., Redd, W. H., \& Cutmore, T. R. (1997). Imagery in human classical conditioning. Psychological Bulletin, 122(1), 89.

Dasgupta, N. (2004). Implicit ingroup favoritism, outgroup favoritism, and their behavioral manifestations. Social Justice Research, 17(2), 143-169.

Dasgupta, N. (2009). Mechanisms underlying the malleability of implicit prejudice and stereotypes: The role of automaticity and cognitive control. In T. D. Nelson (Ed.), Handbook of prejudice, stereotyping, and discrimination (pp. 267-284). Psychology Press.

Dirksmeier, P. (2014). Are urbanites more permissive? Germany's urban geography of prejudice. Urban Affairs Review, 50(6), 835-863.

Dong, P., Dai, X., \& Wyer, R. S., Jr. (2015). Actors conform, observers react: The effects of behavioural synchrony on conformity. Journal of Personality and Social Psychology, 108(1), 60. https://doi.org/10.1037/pspi0000001.

Driskell, J. E., Copper, C., \& Moran, A. (1994). Does mental practice enhance performance? Journal of Applied Psychology, 79(4), 481.

Fadiga, L., \& Craighero, L. (2004). Electrophysiology of action representation. Journal of Clinical Neurophysiology, 21(3), 157-169.

Fawcett, C., \& Tunçgenç, B. (2017). Infants' use of movement synchrony to infer social affiliation in others. Journal of Experimental Child Psychology, 160, 127-136.

Garcia, S. M., Weaver, K., Moskowitz, G. B., \& Darley, J. M. (2002). Crowded minds: The implicit bystander effect. Journal of Personality and Social Psychology, 83(4), 843.

Good, A., Choma, B., \& Russo, F. A. (2017). Movement synchrony influences intergroup relations in a minimal groups paradigm. Basic and Applied Social Psychology, 39(4), 231-238.

Goodwin, M., \& Milazzo, C. (2015). Britain, the European union and the referendum: What drives euroscepticism (Vol. 6). London: Chatham House.

Gurin, P. (1999). Expert report of patricia gurin. In The compelling need for diversity in higher education. Gratz et al. v. Bollinger, et al., No. 97-75321 (E.D. Mich.) Ann Arbor: University of Michigan.

Hagen, E. H., \& Bryant, G. A. (2003). Music and dance as a coalition signalling system. Human Nature, 14(1), 21-51.

Halpern, A. R. (1988). Mental scanning in auditory imagery for songs. Journal of Experimental Psychology. Learning, Memory, and Cognition, 14(3), 434

Hodson, G. (2011). Do ideologically intolerant people benefit from intergroup contact? Current Directions in Psychological Science, 20(3), 154-159.
Holoien, D. S. (2016). whites' desire to affiliate and perceived understanding in interracial interactions. Journal of Experimental Social Psychology, 62, 7-16.

Homola, J., \& Tavits, M. (2018). Contact reduces immigration-related fears for leftist but not for rightist voters. Comparative Political Studies, 51(13), 1789-1820.

Hove, M. J., \& Risen, J. L. (2009). It's all in the timing: Interpersonal synchrony increases affiliation. Social Cognition, 27(6), 949-961.

Hoyt, C. L., \& Goldin, A. (2016). Political ideology and American intergroup discrimination: A patriotism perspective. The Journal of Social Psychology, 156(4), 369-381.

Hunsinger, M., Livingston, R., \& Isbell, L. (2014). Spirituality and intergroup harmony: Meditation and racial prejudice. Mindfulness, 5(2), 139-144.

Kelly, D. J., Liu, S., Lee, K., Quinn, P. C., Pascalis, O., Slater, A. M., et al. (2009). Development of the other-race effect during infancy: Evidence toward universality?. Journal of Experimental Child Psychology, 104(1), 105-114.

Kende, Á. (2000). The Hungary of otherness: The Roma (Gypsies) of Hungary. Journal of European Area Studies, 8(2), 187-201.

Krausova, A., \& Vargas-Silva, C. (2013). The migration observatory briefing. London: Census Profile.

Lakens, D. (2010). Movement synchrony and perceived entitativity. Journal of Experimental Social Psychology, 46(5), 701-708.

Lakens, D., \& Stel, M. (2011). If they move in sync, they must feel in sync: Movement synchrony leads to attributions of rapport and entitativity. Social Cognition, 29(1), 1-14.

Landers, D. M. (1983). The effects of mental practice on motor skill learning and performance: A meta-analysis. Journal of Sport Psychology, 5(1), 25-27.

Lee, N., Morris, K., \& Kemeny, T. (2018). Immobility and the Brexit vote. Cambridge Journal of Regions, Economy and Society, 11(1), 143-163.

Leung, A. K. Y., \& Chiu, C. Y. (2010). Multicultural experience, idea receptiveness, and creativity. Journal of Cross-Cultural Psychology, 41(5-6), 723-741.

Lumsden, J., Miles, L. K., \& Macrae, C. N. (2012). Perceptions of synchrony: Different strokes for different folks? Perception, 41(12), 1529-1531.

Lynott, D., Walsh, M., McEnery, T., Connell, L., Cross, L., \& Marsh, K. (2019). Are you what you read? Predicting implicit attitudes towards immigration based on linguistic distributional cues from newspaper readership. Frontiers in Cognitive Science, 10, 842.

McCann, P. (2016). The UK regional-national economic problem: Geography, globalisation and governance. Abingdon: Routledge.

McNeil, W. H. (1995). Keeping together in time: Dance and drill in human history. Cambridge, MA: Harvard University Press.

McPherson, M., Smith-Lovin, L., \& Cook, J. M. (2001). Birds of a feather: Homophily in social networks. Annual Review of Sociology, 27(1), 415-444.

Merker, B. (2000). Synchronous chorusing and human origins. In N. L. Wallin, B. Merker, \& S. Brown (Eds.), The origins of music (pp. 315-327). Cambridge, MA: MIT Press.

Miles, L. K., Lumsden, J., Richardson, M. J., \& Macrae, C. N. (2011). Do birds of a feather move together? Group membership and behavioural synchrony. Experimental Brain Research, 211(3-4), 495-503.

Miles, L. K., Nind, L. K., \& Macrae, C. (2009). The rhythm of rapport: Interpersonal synchrony and social perception. Journal of Experimental Social Psychology, 45(3), 585-589.

Oishi, S. (2010). The psychology of residential mobility: Implications for the self, social relationships, and well-being. Perspectives on Psychological Science, 5(1), 5-21. 
Park, A., Bryson, C., \& Curtis, J. (Eds.). (2014). British Social Attitudes 31. NatCen.

Pearce, E., Launay, J., MacCarron, P., \& Dunbar, R. I. (2017). Tuning into others: Exploring relational and collective bonding in singing and non-singing groups over time. Psychology of Music, 45(4), 496-512.

Pearce, E., Launay, J., van Duijn, M., Rotkirch, A., David-Barrett, T., \& Dunbar, R. I. (2016). Singing together or apart: The effect of competitive and cooperative singing on social bonding within and between sub-groups of a university Fraternity. Psychology of Music, 44(6), 1255-1273.

Pettigrew, T. F., \& Tropp, L. R. (2006). A meta-analytic test of intergroup contact theory. Journal of Personality and Social Psychology, 90(5), 751.

Phillips, M., \& Phillips, T. (1998). Windrush: The irresistible rise of multi-racial Britain. London: HarperCollins.

Piekut, A., \& Valentine, G. (2017). Spaces of encounter and attitudes towards difference: A comparative study of two European cities. Social Science Research, 62, 175-188.

Reddish, P., Fischer, R., \& Bulbulia, J. (2013). Let's dance together: Synchrony, shared intentionality and cooperation. PLOS ONE, $8(8)$, e71182.

Reimer, N. K., Becker, J. C., Benz, A., Christ, O., Dhont, K., Klocke, U., et al. (2017). Intergroup contact and social change: Implications of negative and positive contact for collective action in advantaged and disadvantaged groups. Personality and Social Psychology Bulletin, 43(1), 121-136.

Tadmor, C. T., Satterstrom, P., Jang, S., \& Polzer, J. T. (2012). Beyond individual creativity: The superadditive benefits of multicultural experience for collective creativity in culturally diverse teams. Journal of Cross-Cultural Psychology, 43(3), 384-392.

Tajfel, H. (1982). Social identity and intergroup relations. Cambridge: Cambridge University Press.

Tamborini, R., Novotny, E., Prabhu, S., Hofer, M., Grall, C., Klebig, B., et al. (2018). The effect of behavioral synchrony with black or white virtual agents on outgroup trust. Computers in Human Behavior, 83, 176-183.

Tarr, B., Launay, J., Cohen, E., \& Dunbar, R. (2015). Synchrony and exertion during dance independently raise pain threshold and encourage social bonding. Biology Letters, 11(10), 20150767.

Tunçgenç, B., \& Cohen, E. (2016). Movement synchrony forges social bonds across group divides. Frontiers in Psychology, 7 , 782.

Turner, J. C. (2010). Social categorization and the self-concept: A social cognitive theory of group behavior. In T. Postmes \& N. R. Branscombe (Eds.), Key readings in social psychology. Rediscovering social identity (pp. 243-272). New York, NY: Psychology Press.

Utsey, S. O., Chae, M. H., Brown, C. F., \& Kelly, D. (2002). Effect of ethnic group membership on ethnic identity, race-related stress, and quality of life. Cultural Diversity and Ethnic Minority Psychology, 8(4), 366.

Vesper, C., Knoblich, G., \& Sebanz, N. (2014). Our actions in my mind: Motor imagery of joint action. Neuropsychologia, 55, $115-121$.

Webb, C. E., Rossignac-Milon, M., \& Higgins, E. T. (2017). Stepping forward together: Could walking facilitate interpersonal conflict resolution? American Psychologist, 72(4), 374.

Wiltermuth, S. (2012). Synchronous activity boosts compliance with requests to aggress. Journal of Experimental Social Psychology, 48(1), 453-456.

Wrench, J., Rea, A., \& Ouali, N. (Eds.). (2016). Migrants, ethnic minorities and the labour market: Integration and exclusion in Europe. Berlin: Springer.

Zatorre, R. J., Halpern, A. R., Perry, D. W., Meyer, E., \& Evans, A. C. (1996). Hearing in the mind's ear: A PET investigation of musical imagery and perception. Journal of Cognitive Neuroscience, 8(1), 29-46.

Publisher's Note Springer Nature remains neutral with regard to jurisdictional claims in published maps and institutional affiliations. 